\title{
Early urinary diversion facilitates stent placement and conservative management of surgical ureteric injuries
}

\author{
Ranjit Chaudhary, ${ }^{1}$ Jyoti Nath Modi, ${ }^{2}$ Nidhi Jain, ${ }^{2}$ Rakesh Biswas ${ }^{3}$
}

${ }^{1}$ Unit of Urology, Department of Surgery, People's College of Medical Sciences, Bhopal, Madhya Pradesh, India ${ }^{2}$ Department of Obstetrics and Gynaecology, People's College of Medical Sciences, Bhopal, Madhya Pradesh, India ${ }^{3}$ LN Medical College and Research Center, Bhopal, India

\section{Correspondence to}

Professor Rakesh Biswas, rakesh7biswas@gmail.com

Accepted 20 January 2015

\section{DESCRIPTION}

A 42-year-old woman presented with continuous urinary discharge from the vagina. She had undergone abdominal hysterectomy for adenomyosis and started leaking urine from the vagina on the 12th postoperative day. On per speculum examination, continuous discharge of clear urine was seen from suture line at vault apex. A three swab test was suggestive of a ureteric fistula as the higher swab was wet but not dye stained. Ultrasonogram revealed moderate hydroureteronephrosis on the right side. A contrast CT scan (figures 1-3) showed a right lower ureteric injury with extravasation of contrast and irregular tract draining freely into the vagina. No dye was seen draining into the urinary bladder from the right ureter. The filling defects seen along the course of the left ureter are artefacts secondary to reconstruction of images.

An $8 \mathrm{Fr}$ per cutaneous nephrostomy was performed under ultrasonography guidance without fluoroscopy, and on the postoperative skiagram we realised that the tube was resting in the ureter (figure 4). Though the nephrostomy tube is intended not to traverse the pelviureteric junction, we did not withdraw the tip in the pelvis as we expected it to drain better.

Generally, nephrostomy tubes that we employ are of soft material expected to cause minimal or no injury to the ureter. However, there is always a small risk involved and we were lucky not to have experienced any complications even though the curl was resting in the ureter.

Subsequent to this the urinary leak from the vagina subsided.

After 2 weeks, a nephrostomogram was performed (figure 5). It showed a dilated ureter with

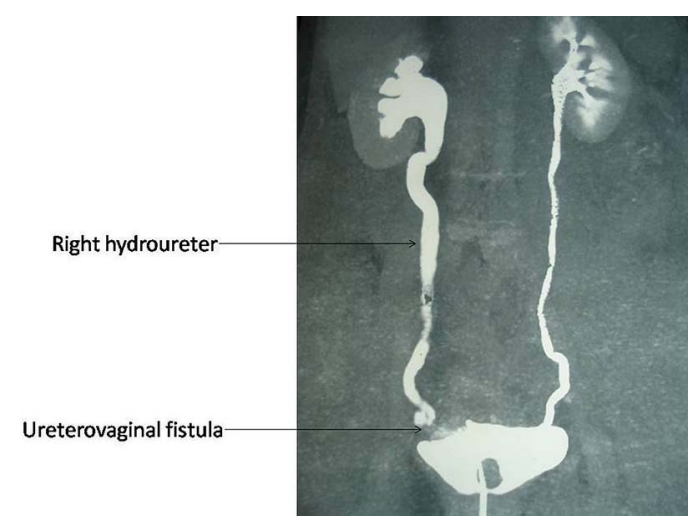

Figure 1 Contrast CT scan depicting right lower ureteric injury.

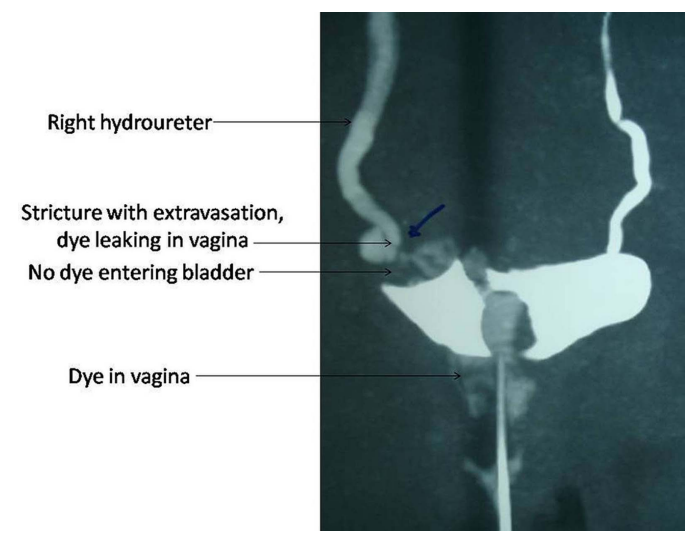

Figure 2 Contrast CT scan depicting right lower ureteric injury and ureterovaginal fistula.

abrupt narrowing of the lower segment; however, the dye was passing into the bladder suggestive of a partial ureteric stricture. Although there was slight extravasation at the site of narrowing, no communication with the vagina was seen. This suggested obliteration of the fistula secondary to diversion.

In lithotomy position under spinal anaesthesia, an $8 \times 9.8 \mathrm{Fr}$ ureteroscope was introduced in the right ureteric orifice and retrograde pyelography was carried out (figure 6). It showed a lower ureteric stricture about $2 \mathrm{~cm}$ proximal to the vesicoureteric junction with the dye passing across. We were unable to negotiate a hydrophilic guide wire $\left(0.035^{\prime \prime}\right.$ Terumo) across the stricture (figure 7 ). The patient was turned prone and saline was pushed through the nephrostomy tube in an attempt to dilate the stricture. After several attempts we were able to negotiate a $0.035^{\prime \prime}$ Zebra

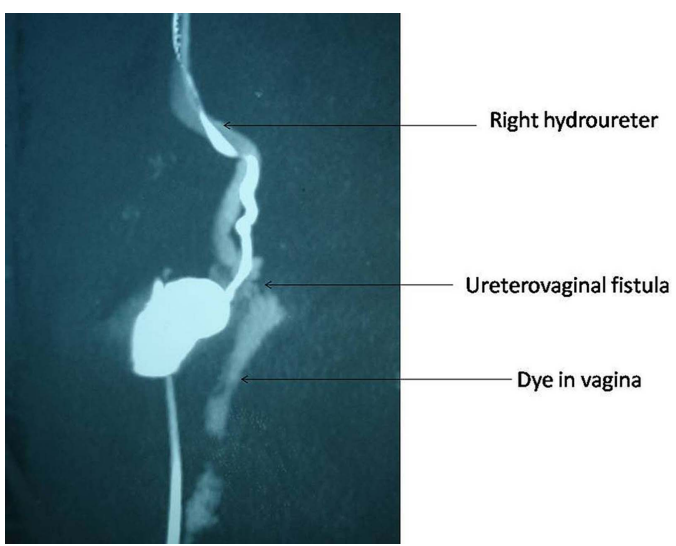

Figure 3 Contrast CT scan (sagittal section) depicting right ureterovaginal fistula. 


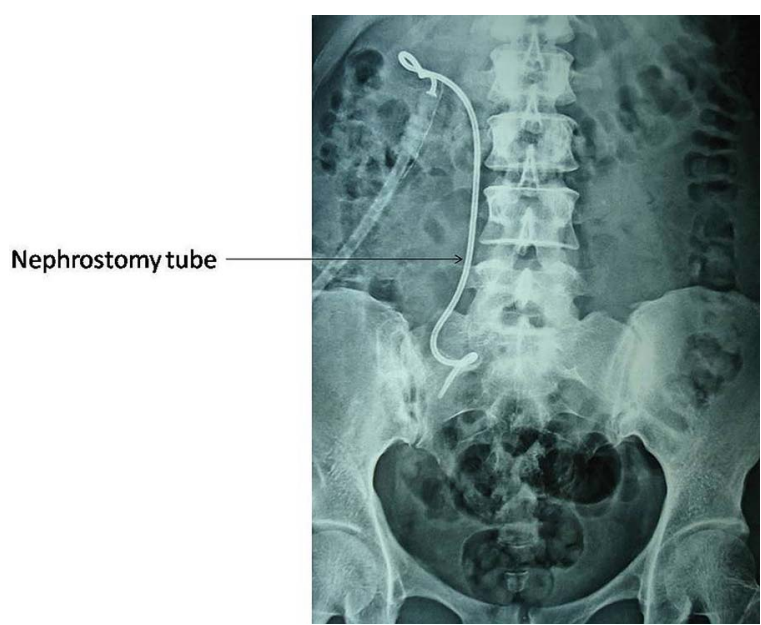

Figure 4 Right nephrostomy tube seen.

guide wire across the stricture into the urinary bladder. Over this wire, a $6 \mathrm{Fr} / 26 \mathrm{~cm}$ double J stent was placed (figure 8). The urethral catheter was removed and the patient was discharged the next day. The stent was removed at 6 weeks and the patient continues to remain dry. Ultrasonogram showed resolution of the hydroueteronephrosis. We plan to perform imaging studies 6 weeks after stent removal to assess the status of the right lower ureter.

\section{DISCUSSION}

Ureterovaginal fistulae are among the most serious complications in gynaecological surgery. They are more detrimental than vesicovaginal fistulae because when left untreated, they may lead to progressive deterioration of renal functions.

In our practice, we advocate a trial of endoscopic management for ureterovaginal fistulae if imaging studies demonstrate a partial ureteric injury with some communication with the bladder. In such cases, a trial of double J stenting is recommended. ${ }^{1-3}$

However, in the reported case, the CT scan did not show any communication with the bladder, perhaps because all the urine was draining into the vagina. Therefore we performed a urinary diversion by inserting a per cutaneous nephrostomy tube of $8 \mathrm{Fr}$ under ultrasonography guidance.

Urinary diversion was the key to success in this case, as diversion led to complete obliteration of the fistulous tract. As it was a partial ureteric injury, patency was demonstrated on nephrostomogram as well as on retrograde pyelography. In order to stent the patient, it was imperative to negotiate a guide wire

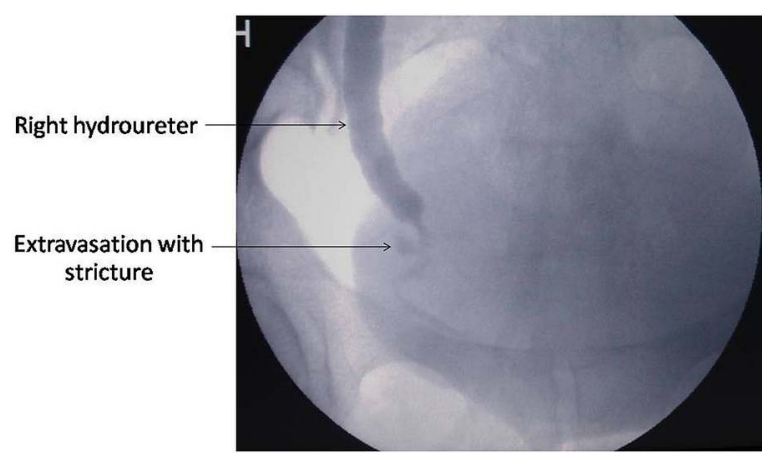

Figure 5 Right nephrostomogram.

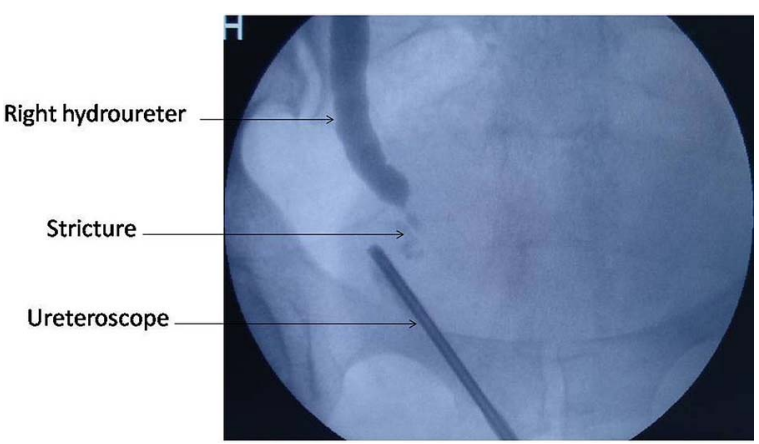

Figure 6 Right retrograde pyelogram.

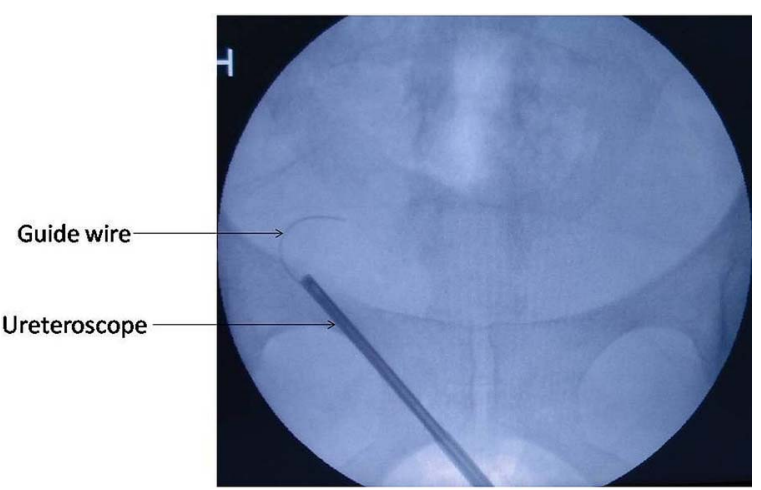

Figure 7 Shows the inability to negotiate guide wire across the stricture retrogradely.

across the stricture. If passing of a guide wire had been attempted antegradely before the obliteration of the fistula, it would have entered the fistulous tract rather than going across a strictured ureteric segment. However, subsequent to diversion, as the fistulous tract obliterated, the guide wire found its way across the strictured segment.

We recommend a trial of stenting in cases of ureterovaginal fistulas. In cases of partial ureteric injuries, stenting may be a curative procedure obviating the need for a ureteric reimplantation. However, all cases managed by endoscopic approach must be followed up by imaging studies after stent removal to rule out any ureteric narrowing.

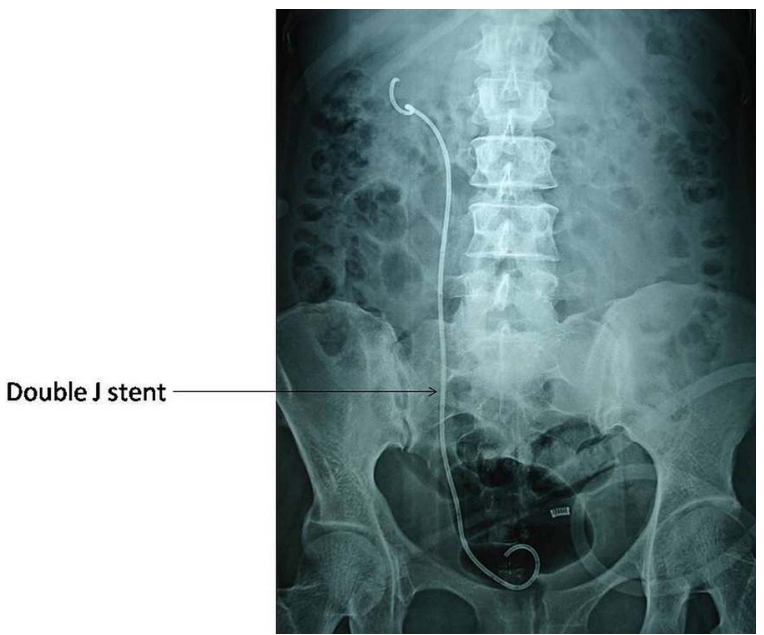

Figure $8 \quad 6 \mathrm{Fr} / 26 \mathrm{~cm}$ double J stent placed. 


\section{Learning points}

- Ureteroscopic stenting should be considered as the primary mode of intervention in cases of ureterovaginal fistula with a partial ureteric stricture.

- However, in cases where imaging studies fail to demonstrate communication with the bladder, it may be prudent to achieve urinary diversion by a nephrostomy and subsequently carry out an assessment after 10-14 days.

- All cases managed by endoscopic approach must be followed up by imaging studies after stent removal.
Contributors RC and JNM operated on the patient. NJ and RB helped in the preparation of the manuscript.

Competing interests None.

Patient consent Obtained.

Provenance and peer review Not commissioned; externally peer reviewed.

\section{REFERENCES}

1 Rajamaheswari N, Chhikara AB, Seethalakshmi K. Management of ureterovaginal fistulae: an audit. Int Urogynecol I 2013;24:959-62.

2 Elabd S, Ghoniem G, Elsharaby M, et al. Use of endoscopy in the management of postoperative ureterovaginal fistula. Int Urogynecol I Pelvic Floor Dysfunc 1997:8:185-90.

3 Koonings PP, Huffman JL, Schlaerth JB. Ureteroscopy: a new asset in the management of postoperative ureterovaginal fistulas. Obstet Gynecol 1992;80(3 Pt 2):548-9.

Copyright 2015 BMJ Publishing Group. All rights reserved. For permission to reuse any of this content visit http://group.bmj.com/group/rights-licensing/permissions.

BMJ Case Report Fellows may re-use this article for personal use and teaching without any further permission.

Become a Fellow of BMJ Case Reports today and you can:

- Submit as many cases as you like

- Enjoy fast sympathetic peer review and rapid publication of accepted articles

- Access all the published articles

- Re-use any of the published material for personal use and teaching without further permission

For information on Institutional Fellowships contact consortiasales@bmjgroup.com

Visit casereports.bmj.com for more articles like this and to become a Fellow 